\title{
Evaluation of the BGM-3 sea gravity meter system onboard R/V Conrad
}

\author{
Robin E. Bell* and A. B. Watts*
}

\begin{abstract}
The first Bell Aerospace BGM-3 Marine Gravity Meter System available for academic use was installed on $R / V$ Robert $D$. Conrad in February, 1984. The BGM-3 system consists of a forced feedback accelerometer mounted on a gyrostabilized platform. Its sensor (requiring no cross-coupling correction) is a significant improvement over existing beam and spring-type sea gravimeters such as the GSS-2.

A gravity survey over the Wallops Island test range together with the results of subsequent cruises allow evaluation of the precision, accuracy, and capabilities of the new system. Over the test range, the BGM-3 data were compared directly to data obtained by a GSS-2 meter onboard $R / V$ Conrad. The rms discrepancy between free-air gravity anomaly values at intersecting ship tracks of $R / V$ Conrad was $\pm 0.38 \mathrm{mGal}$ for BGM-3
\end{abstract}

\section{INTRODUCTION}

The first successful marine gravity measurements were obtained onboard a submarine during 1923 to 1937 (Vening Meinesz, 1929, 1941). The measuring apparatus consisted of free-swinging pendulums mounted in a gimbal frame. By measuring the differences in motion of two pairs of "fictitious" pendulums, accuracies of about 5-15 mGal were obtained. Later systems incorporated corrections for horizontal accelerations (Browne, 1937) which significantly improved the accuracy of the pendulum measurements. Between 1936 and 1959 more than 5000 measurements from all the world's oceans were obtained using this system (Worzel, 1965). The primary limitations were the extremely long time required for each measurement and the inability to adapt the apparatus for use on surface ships.

By the late 1950 s, sea gravity meter systems had become available that could measure gravity at sea continuously and in a wide range of sea states. The first sensors (both modifications of land gravity meters) were developed by GrafAskania (GSS-2 meter; Graf, 1958) and Lacoste-Romberg (L\&R meters; Lacoste, 1959). These systems consisted of heav- compared to $\pm 1.60 \mathrm{mGal}$ for the GSS-2. Moreover, BGM-3's platform recovered from abrupt changes in ship's heading more rapidly than did the platform of GSS-2.

The principal factor limiting the accuracy of sea gravity data is navigation. Over the test range, where navigation was by Loran $\mathrm{C}$ and transit satellite, a two-step filtering of the ship's velocity and position was required to obtain an optimal Eötvös correction. A spectral analysis of 1 minute values of the Eötvös correction and the reduced free-air gravity anomaly determined the filter characteristics. To minimize the coherence between the Eötvös and free-air anomaly, it was necessary to prefilter the ship's position and velocity. Using this procedure, reduced free-air gravity anomalies with wavelengths as small as a few kilometers can be resolved. 
By the late 1960 s, a significant effort was being made to design axially symmetric sensors to eliminate the crosscoupling error. The two main types of sensors developed were the vibrating string accelerometer (VSA) and the forcedfeedback accelerometer. The Massachusetts Institute of Technology (MIT) and Tokyo Surface Ship Gravimeter VSA systems measure changes in gravity by monitoring variations in the resonant frequency of short, vertical strings. Because the resonant frequency is proportional to the square root of gravity, nonlinear "rectification" errors result. Unlike the Tokyo Surface Ship Gravity meter (Tomoda and Kanamori, 1962), the MIT sensor (Wing, 1969) incorporates two strings that act in opposition to eliminate this nonlinear error. Bowin et al. (1972), using the MIT sensor, reported accuracies of 1 to 3 mGal. In the forced-feedback accelerometer built by Bell Aerospace and by Bodenseewerk (formerly Askania), changes in the current in a coil moving vertically between two permanent magnets are measured.

Of the new generation of axially symmetric sea gravity systems, only the Bodenseewerk KSS-30 and the Bell Aerospace BGM-3 systems are presently available. The KSS-30 system has been in use since 1981, primarily by Bundesannstalt fur Geowissen schaften und Rohstoffe in West Germany by the University of Hamburg, by Centre Nationale l'EXploitation des Oceans in France, and by the Bedford Institute of Oceanography in Canada. Pierce et al. (1984) reported on the operation of the KSS-30 offshore Canada where they found that, depending upon the type of navigation, the system was accurate to \pm 0.6 to $\pm 2.0 \mathrm{mGal}$. The BGM-3 has been used by the U. S. Department of Defense and the oil industry. However, the only previously reported accuracies are $\pm 1.9 \mathrm{mGal}$ for an unpublished National Ocean Survey cruise in the Pacific (Burnfield, 1981).

The purpose of this paper is to describe our experiences with a BGM-3 sea gravity meter system installed on the $R / V$ Conrad. We attempt to (1) assess the systems accuracy through analysis of the discrepancy of free-air gravity anomalies at intersecting ship tracks, (2) determine the system's response time to the type of maneuvers normally made in marine geophysical surveys, (3) determine the system's lower limit of resolution to changes in the gravity field, (4) determine the system's sensitivity to the quality of navigation, and (5) assess the significance of the system's capabilities in view of the recent development of other high-resolution tools such as satellite altimetry and the global positioning system (GPS).

\section{DESCRIPTION OF THE BGM-3 SEA GRAVITY METER SYSTEM}

The BGM-3 sea gravity meter system manufactured by Bell Aerospace, Textron, Buffalo, New York consists of an inertial navigation-grade accelerometer mounted on a gyrostabilized platform, and a data handling system. This system is a third

A.

BGM-3 Accelerometer

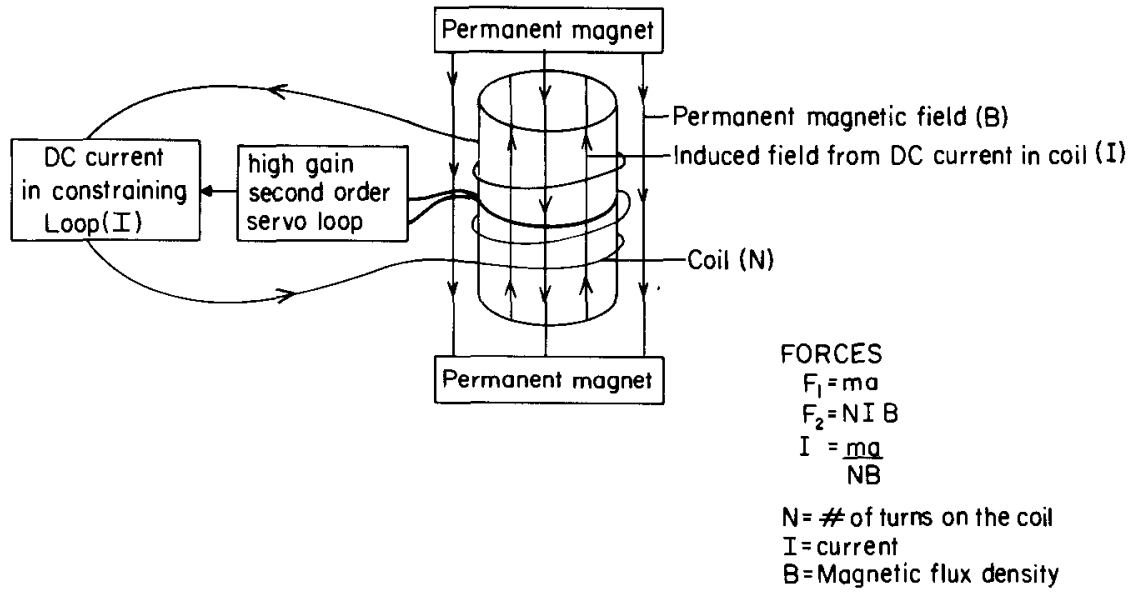

B.

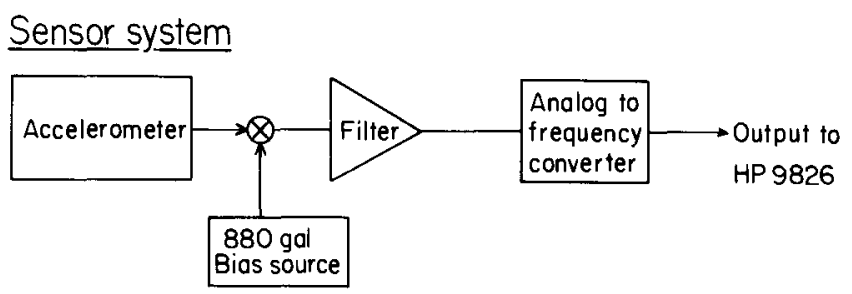

FIG. 1. Schematic of BGM-3 sensor subsystem. (a) BGM-3 Accelerometer configuration with proof mass wrapped in coil between two permanent magnets. Balance of forces $F 1=$ local gravitational force, $F 2=$ electromagnetic force induced by current in coil where $m=$ mass of proof mass, $a=$ local vertical accelerations, $N=$ number of turns on coil, and $B=$ magnetic flux density. (b) Sensor system showing summing of signal from accelerometer with bias source, R-C filter of signal, conversion of this analog signal to digital signal, and final output to data handling system. 
generation gravity meter system that supersedes the BGM-1 and BGM-2 systems.

The BGM-3 sensor is a Model XI accelerometer (Bell Aerospace, 1978), shown schematically in Figure 1a. The accelerometer is a "proof mass" wrapped in a coil that is constrained to move vertically between two permanent magnets. The physical principle of the sensor design is that a balance exists between the gravitational force acting on the proof mass and the electromagnetic force induced in the coil. This force balance maintains the proof mass in a constant (null) position. The current in the coil varies proportionally to changes in vertical accelerations. At sea, these accelerations are the sum of the Earth's gravitational acceleration and vertical accelerations acting on the ship. Changes in the position of the proof mass are detected by a second-order servo loop which regulates the current in the coil and drives the proof mass back to its null position.

The output from the accelerometer is a current proportional to vertical accelerations in the range of 0 to $200 \mathrm{Gal}$. By summing the output with a reference bias of $880 \mathrm{Gal}$, the system can respond to the range of vertical accelerations normally encountered at sea. This current is then filtered with a simple R-C filter with a time constant of $4.50 \mathrm{~s}$ to prevent leakage of high frequencies. Finally, the filtered analog signal is converted to a digital pulse rate for output to the data handling system.

Figure 2 shows the sensor housing and associated electronics as installed on $R / V$ Conrad. The sensor housing contains the accelerometer $(3.4 \mathrm{~cm}$ high by $2.3 \mathrm{~cm}$ diameter mounted inside double ovens to maintain thermal stability. The associated electronics (contained in a single drawer) includes power regulators, system monitoring circuits, and an interface with the data handling system.

In a 280 day monitoring period prior to its installation, Bell Aerospace (R. N. Burnfield, Pers. comm.) evaluated the static sensitivity of the sensor and its drift characteristics. Figure 3 shows a power spectrum (normalized for frequency) of the sensor output in a stable environment. The spectrum shows well-defined peaks corresponding to the Mf (fortnightly), M2 (diurnal), and K1 (semidiurnal) solid-Earth tides. The Mf tidal component's value of about $10 \mu \mathrm{Gal}$ indicates the lower limit of the static sensitivity of the sensor to changes in gravity.

As a result of their observations during the monitoring period, Bell Aerospace predicted a drift rate of $0.091 \mathrm{mGal} /$ day for the sensor installed on $R / V$ Conrad. Figure 4 shows the drift rate of the system for a 430 day period subsequent to installation. The mean and $\mathrm{rms}$ rates for the period were 0.064 $\mathrm{mGal} / \mathrm{day}$ and $\pm 0.026 \mathrm{mGal} / \mathrm{day}$ respectively. For the period 210 to 310 days, however, unusually low and high rates were observed. These rates may reflect the complete loss of system power that occurred on day 235 between Bermuda and Pureto Rico. Bell Aerospace (R. N. Burnfield, Pers. comm.) has documented abrupt changes in the drift rate associated with laboratory air conditioning failure and with system power loss. Despite this evidence of the system's sensitivity to thermal perturbations, the overall drift for the operational period is remarkably uniform (Figure 4).

The sensor housing is bolted directly onto the inner gimbal of the two-axis gyrostabilized platform (Figure 2). In addition to the inner and outer gimbals, the system comprises two Honeywell GG111AJ10 minature rate integrating gyroscopes and two horizontal accelerometers. The control power supply (Figure 2b) contains the electronics to monitor the platform motion. The horizontal accelerometers together with the gyroscope pickoff voltages detect the platform motion. The torque motors (Figure 2a) drive the platform through the angle recorded by the gyroscopes until the horizontal accelerometers show zero motion.

The digital pulse rate from the sensor is output to the data handling system (Figure 5). The system, which filters and logs the data, consists of a data buffer, a Hewlett-Packard HP9826A desktop calculator, a Digi-Data tape transport, and a thermal line printer. The data buffer accepts data from a standard clock, the ship's navigation computer, and the sensor, and transmits them to the HP9826A. A weighted average filter is applied to the pulse rate before it is converted to milligals in order to remove accelerations acting on the ship due to ship motions. It is therefore implied in the filtering that accelerations due to ship motions have a characteristic frequency range which differs from accelerations due to geologic sources. The smoothed value $S$ is given by:

$$
S=\sum_{i=1}^{n} W_{i} U_{i}
$$

where $U$ is the unsmoothed value, $n$ is the number of unsmoothed points, and $W_{i}$ is a weighting function of the form

$$
W_{i}=e^{-\left(t_{0}-t_{i}\right)^{2} / 2 \sigma^{2}}
$$

with $t_{0}$ the time of the value sought, $t_{i}$ is the time of the $i$ th value, and $\sigma$ is the half-width of the filter. The manufacturer's recommended value for $\sigma$ is $30 \mathrm{~s}$ which corresponds to a total filter width of 3 minutes $(6 \sigma)$. This $\sigma$ value would, for example, reduce a $5 \mathrm{mGal}$ change in gravity with a period of 1.7 minutes to $1 / e$ of its value while shorter periods would be more greatly attenuated.

In addition to filtering the data, the calculator monitors the system status, converts the pulse rate to milligals, and computes the Eötvös correction, theoretical gravity, and the freeair gravity anomaly. The system output is transmitted to the thermal line printer and the tape drive. An example of the line printer output is shown in Figure 6, illustrating the "realtime" capabilities of the system. Digital recording of the gravity data permits further processing using refined navigation and updated drift rates.

\section{WALLOPS ISLAND BGM-3 EVALUATION EXPERIMENT}

A BGM-3 sea gravity meter system was installed on $R / V$ Conrad on February 1, 1984 in Piermont, NY. The system was installed below a staircase $0.6 \mathrm{~m}$ to the port of the ship's center line and $1.1 \mathrm{~m}$ forward of a water-tight bulkhead separating the gravity room from the engine room. The gyrostabilized platform was bolted directly to a mounting frame using ruggedized shock mounts. Earlier GSS-2 sea gravity systems on $R / V$ Conrad were mounted aft of the BGM-3 gravity room, in the engine room. We believe the new location, together with shock mounts, have eliminated any vibration problems arising form the ship's engines.

After completing a gravity base station tie-in in Piermont, NY (Appendix A), R/V Conrad departed for Norfolk, VA. In addition to the BGM-3 system, $R / V$ Conrad was equipped with a Graf-Askania GSS-2 sea gravity meter mounted on an Aeroflex gyrostabilized platform, a transit satellite navigation system (SATNAV), a Loran C high-frequency radio-ranging system, and a Furuno Doppler speed log which provides over-the-ground velocity information in shallow water. All the 


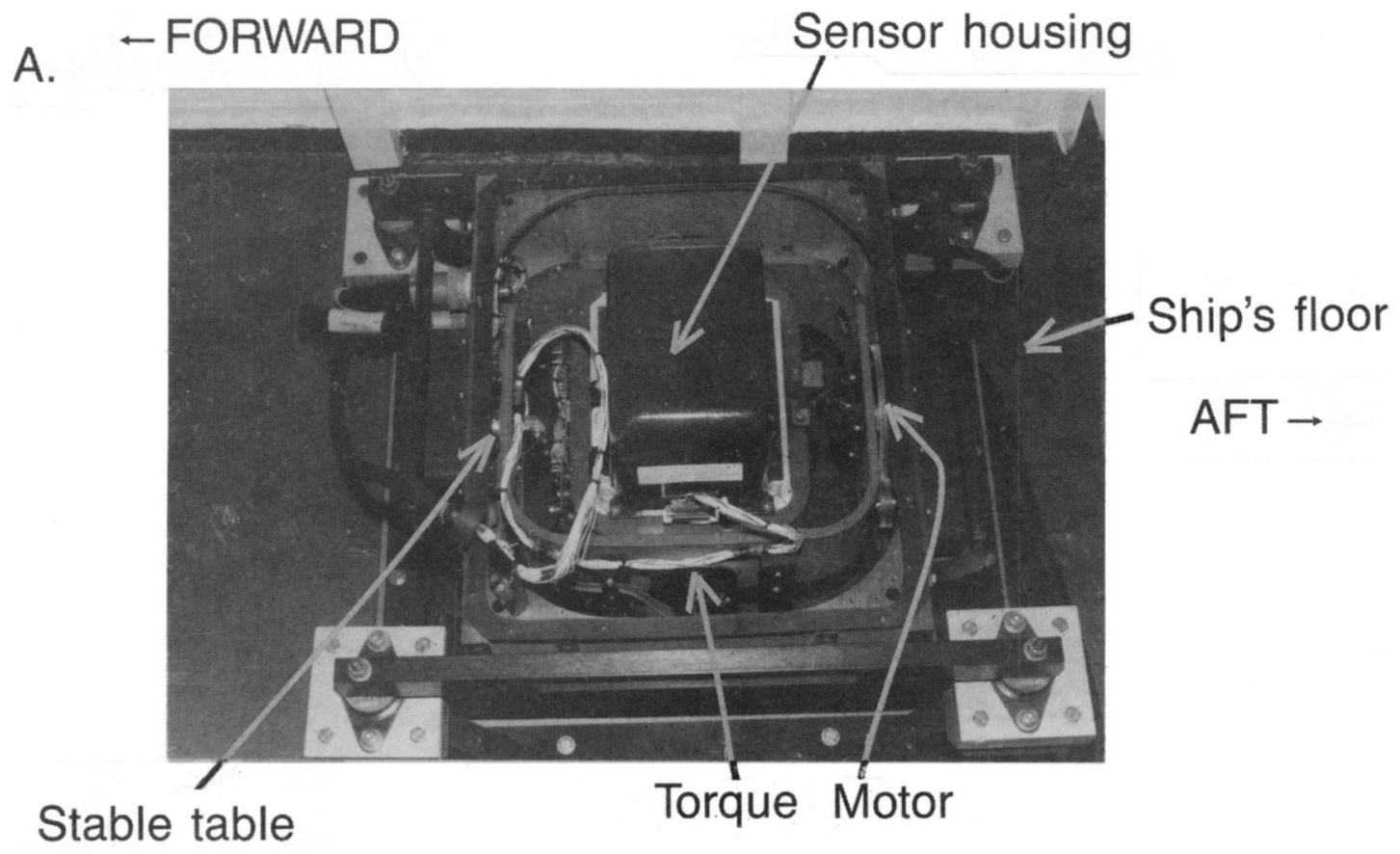

B.

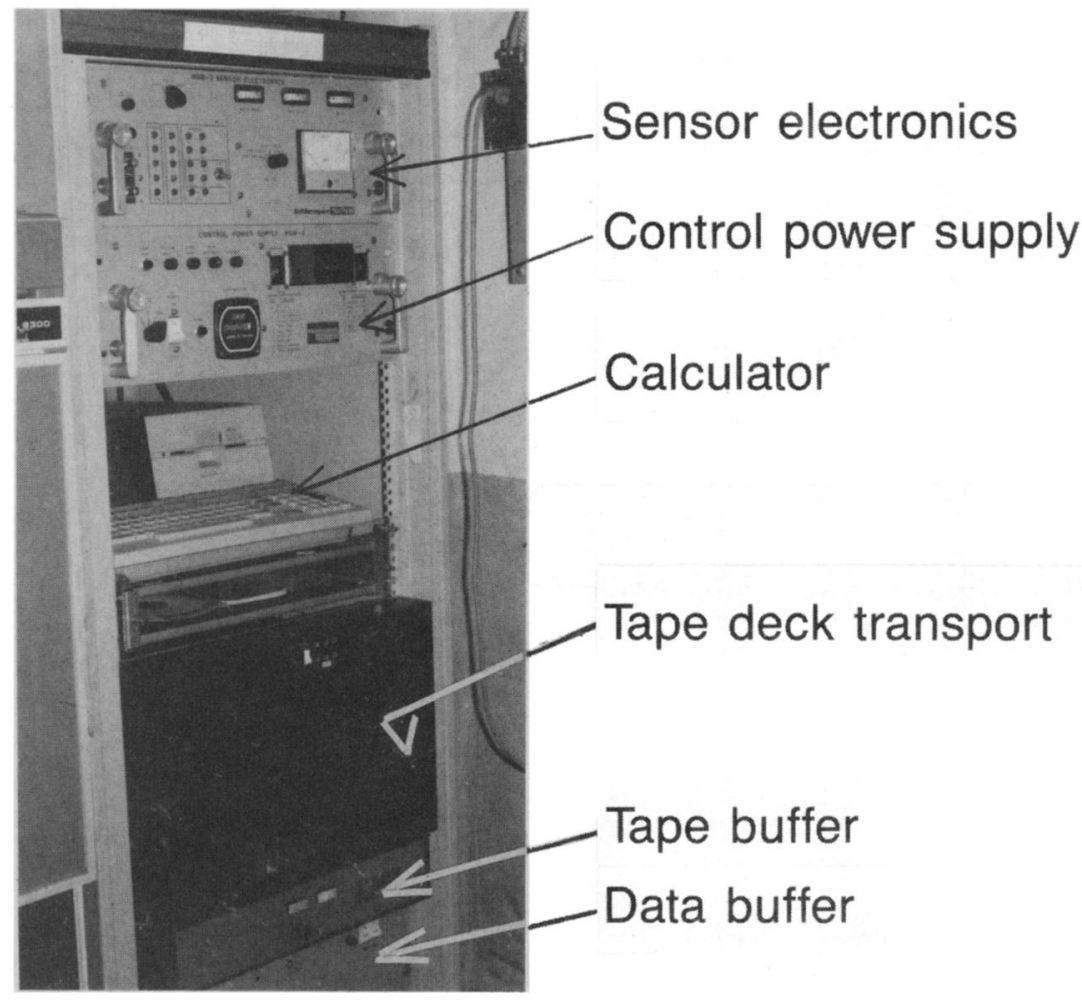

FIG. 2. (a) BGM-3 platform and sensor as mounted on $R / V$ Conrad. Sensor housing and torque motors are normally protected by a cover. Not visible is the gimbal angle modification which provides the vertical reference to the multibeam echo sounding system, Seabeam. (b) Single rack of electronics for BGM-3 on $R / V$ Conrad. The only other equipment not shown here is a thermal line printer and the auxiliary power supply. 


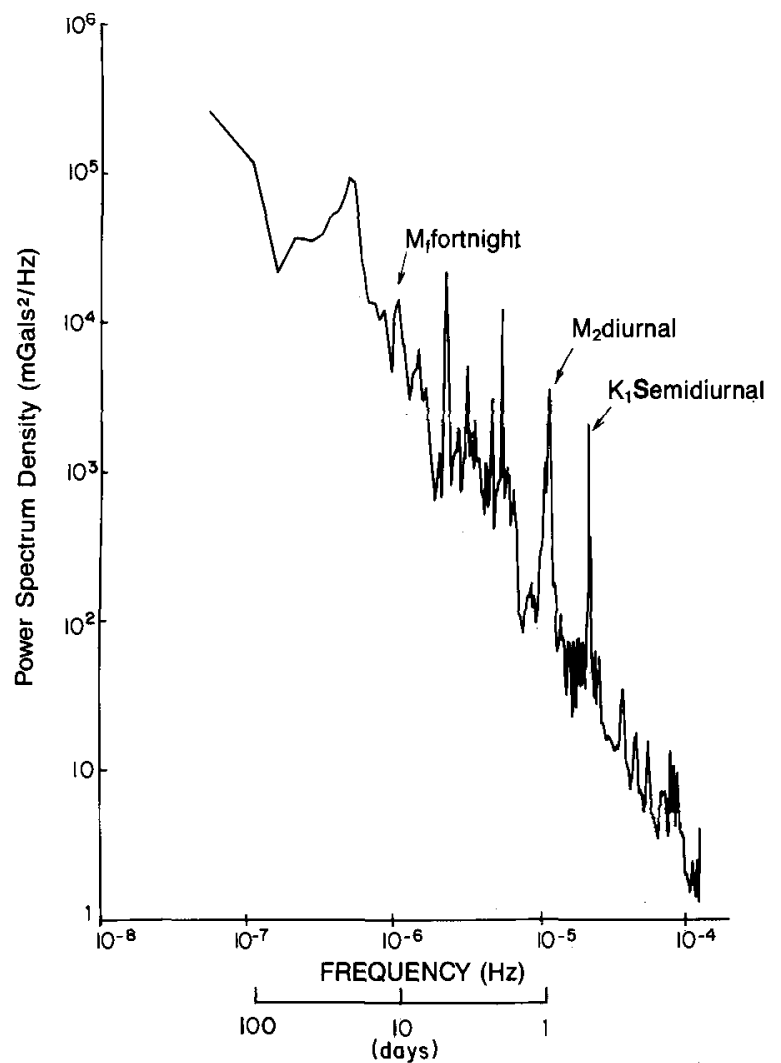

FIG. 3. Power spectrum (normalized for frequency) of sensor output during 280 day monitoring period of BGM-3 output conducted by Bell Aerospace in Buffalo, N.Y., Mf, M2, and $\mathrm{K} 1$ earth tides have clear peaks representing a lower limit of static sensor resolution of $10 \mu \mathrm{Gal}$. Other peaks in sloping spectrum correspond to frequencies predicted by an earth-tide model. navigation data were recorded on a logging system controlled by a Data General Nova 4 computer. After 19 days of a Seabeam survey, $R / V$ Conrad entered the Wallops Island gravity equipment evaluation range. The sea state during the 36 hours of gravity surveying was force 1 , providing optimal operating conditions for both gravimeters.

The Wallops Island test range consists of 173 sea-bottom gravity stations distributed over $4500 \mathrm{~km}^{2}$ (Orlin et al., 1965; Figure 7). The stations were occupied using a LacosteRomberg sea-bottom gravity meter. By analyzing repeat readings at individual stations, Orlin et al. (1965) concluded that the accuracy of the sea-bottom gravity measurements is \pm 0.15 mGal.

A free-air gravity anomaly map of the test range and its vicinity is shown in Figure 7. The map was compiled from sea-bottom measurements (heavy dots), surface ship data (fine dots), and land measurements. The test range is located on a prominent north-south trending free-air gravity anomaly "low." This low, which is subparallel to Appalachian trends, is flanked to the east by a gravity anomaly high of about 80 $\mathrm{mGal}$ associated with the continental shelf edge. The minimum gravity anomaly value over the test range is $-33 \mathrm{mGal}$ and the maximum is $35 \mathrm{mGal}$. The steepest gradients occur about $50 \mathrm{~km}$ east of Cape Charles where they locally reach 1.2 $\mathrm{mGal} / \mathrm{km}$.

The test range experiment allowed comparison of the two surface ship gravity measuring systems, BGM-3 and GSS-2, to the sea-bottom measurements. Figure 8 shows profile A-B (located in Figure 7) which crossed the test range north to south. At the northern end of the profile, the GSS-2 measurements differ by more than $7 \mathrm{mGal}$ from both the BGM-3 and seabottom measurements. The BGM-3 results however, compare well with the sea-bottom measurements. Profile B-C (Figure 7), over the southern end of the range, was traversed three times to test the repeatability of the systems. The BGM-3

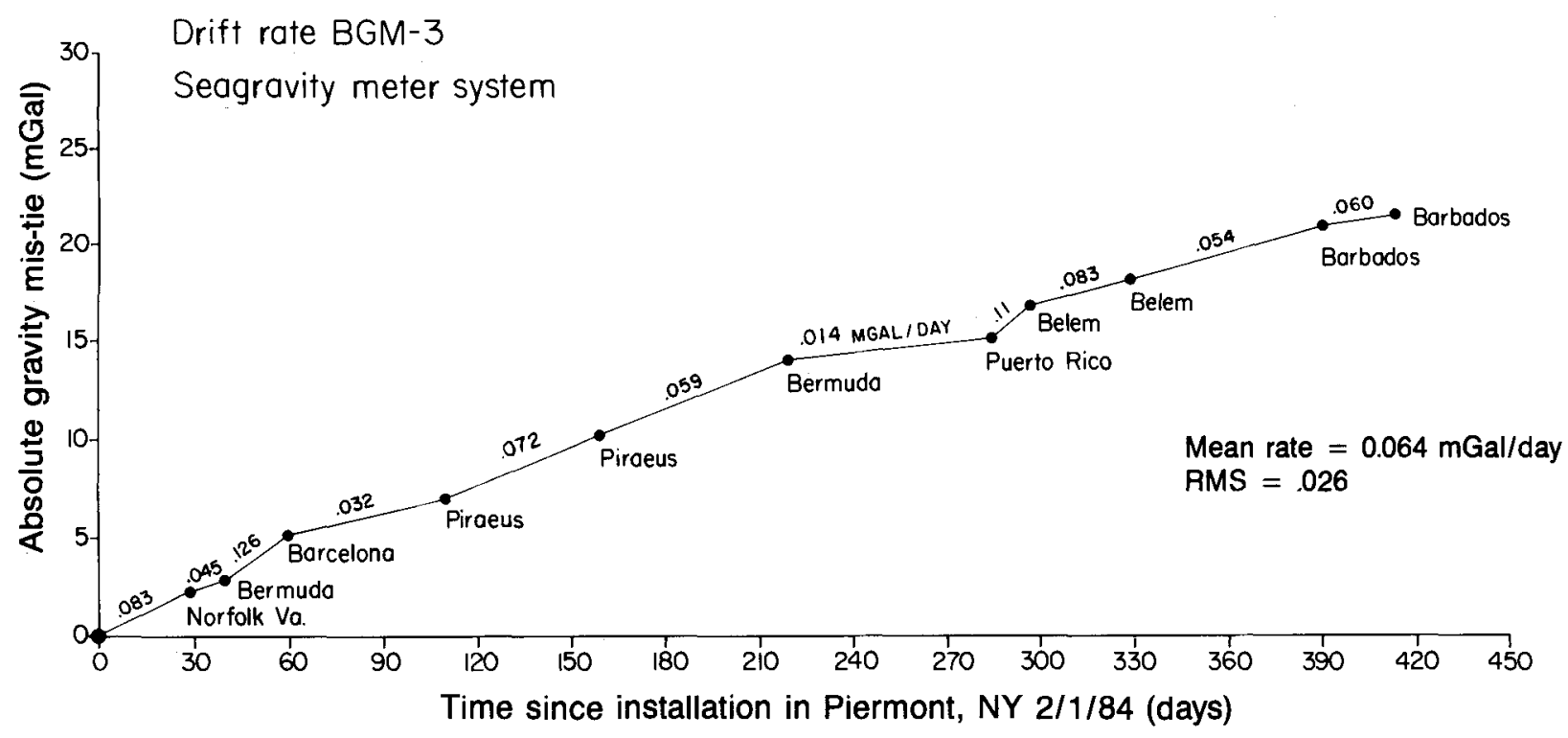

FIG. 4. Drift rate of BGM-3 sensor on $R / V$ Conrad for 430 days following installation. The absolute gravity mis-tie is calculated by setting the measured value in Piermont, N.Y. (February 1984) as zero. The drift rate between each tie is shown in $\mathrm{mGals} / \mathrm{day}$ above the line segments. The drift rate, with two exceptions, Bermuda-Barcelona and BermudaPuerto Rico, is less than the rate predicted $(0.091 \mathrm{mGal} /$ day) by the manufacturer. These exceptions may reflect loss of thermal stability related to loss of ship's power. 
gravity profiles repeat well [root-mean-square (rms) discrepancy $\pm 0.58 \mathrm{mGal}]$, while the GSS-2 profiles show up to 4 $\mathrm{mGal}$ offsets (rms $\pm 1.58 \mathrm{mGal}$ ). The BGM-3 tracks the seabottom measurements well, while the GSS-2 tracks consistently high (by 5 to $7 \mathrm{mGal}$ ). The BGM-3 seems to provide internally consistent measurements, whereas the GSS-2 shows persistent discrepancies, probably due to the slow recovery of the system to ship maneuvers.

In addition to agreeing well with the widely spaced seabottom measurements, the BGM-3 data records shortwavelength information. Some of this information appears to correlate with short-wavelength changes in bathymetry (Figure 9). Thus it is not instrument noise and the BGM-3 system may be capable, in shallow water depths, of resolving features in the bathymetry as small as a few kilometers wide and a few meters high. Other small-scale changes in the gravity anomaly along the profile may reflect either density inhomogeneities in the upper few hundred meters of the sediment solumn or instrument noise.

Examination of the discrepancies in gravity values at intersecting tracklines provides another indication of system repeatability. A histogram of crossover discrepancies (Figure 10) for both instruments in the test range clearly shows the higher repeatability of the BGM-3 (rms $\pm 0.38 \mathrm{mGal}$ ) compared with the GSS-2 (rms $\pm 1.6 \mathrm{mGal})$.

As part of the evaluation, we carried out a number of ship maneuvers to assess the response of the BGM-3 system. The system response is primarily determined by the characteristics of the internal filter which removes the effects of periodic ship motions. We found that for a relatively sharp turn, the
BGM-3 response time was of the order of 3 minutes (Figure 11), significantly less than the response time of the GSS-2, which took as long as 20 minutes to recover from the same turn.

The accuracy of gravity measurements and the ability to recover free-air anomalies at sea are primarily determined by the quality of the navigation. The principal source of error is incorrect computation of the Eötvös correction, given by

$$
\text { Eötvös correction }=7.503 V_{e} \cos \theta+.004154 V_{t}^{2}+\ldots \text {, }
$$

where $V_{e}$ is the easterly component of the over-the-ground velocity (knots), $\theta$ is the latitude, and $V_{t}$ is the velocity vector (knots). To obtain accuracies of better than $1 \mathrm{mGal}$, equation (3) indicates that velocities should be determined to better than .2 knots and the ship's heading, to better than 1 degree. Ideally, no relationship should exist between the Eötvös correction and the reduced free-air gravity anomaly since equation (3) fully describes all the inertial terms sensed by the ship's gravimeter. To quantify the actual relationship, we applied time-series analysis to the calculated Eötvös correction and the resultant free-air gravity anomaly.

Time-series analysis techniques were first applied to the Eötvös correction derived from the raw navigation and then to the correction determined from finely tuned navigation. The raw navigation consisted of Loran fixes supplemented by Satnav position updates. This navigation is known to contain errors (e.g., sky-wave effects) which may become significant in high-resolution surveys. Figure $12 \mathrm{a}$ shows the coherence between the Eötvös correction based on the raw navigation and the associated free-air gravity anomaly calculated from data

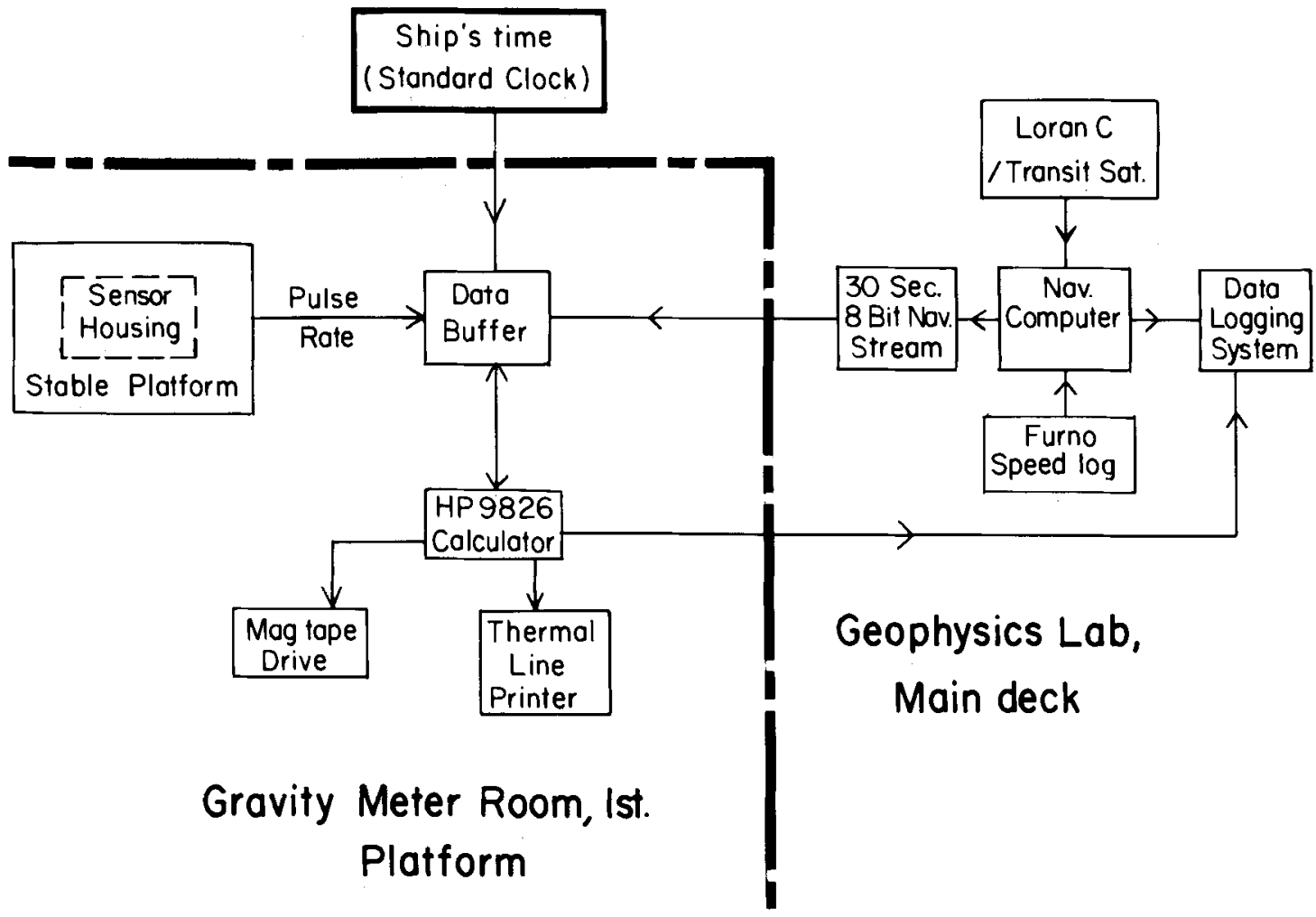

FIG. 5. Gravity and navigation data handling system on $R / V$ Conrad. Arrows show flow of data between components. Heavy line separates instruments located in the gravity meter room and instruments in the Geophysics Lab. 
collected along 11 straight line segments (1 hour duration). There is high coherence (greater than 0.5 ) for all periods, indicating the presence of a significant component of the Eötvös correction in the reduced free-air anomaly. To reduce the coherence, we first smoothed the positions using a 9 minute running average. Figure $12 \mathrm{a}$ shows that this smoothing only reduces the coherence for periods greater than 3.5 minutes. A 5 minute running average filter applied to the velocities derived from the smoothed positions satisfactorily reduces the coherence for all periods. This two-step filtering scheme produces the finely tuned navigation which best accounts for the accelerations due to ship motion recorded by the gravimeter.
To examine the noise levels in the gravimeter data, we constructed power spectra of the reduced free-air gravity anomalies. Figure $12 \mathrm{~b}$ shows the power spectra of the free-air anomaly based on the unfiltered Eötvös correction and the two-step filtering. The spectra for the unfiltered case appear to be flat at periods of less than 5 minutes. The filtered position spectra are flat at greater periods (12 minutes), indicating the corresponding Eötvös correction introduced noise into the reduced freeair anomaly. The spectra associated with the finely tuned navigation appear to be flat at shorter periods, about 4.5 minutes. We believe this lower limit indicates the minimum resolving power of the reduced free-air anomaly. A period of $4.5 \mathrm{~min}$ -

\author{
SENSOR SCALE FACTOR (mGal/pps) 4.951830 \\ CORRECTED BIAS (mGal) 855917.0 \\ DRIFT (mGal/day) -0.091 \\ PLOT SCALE (mGal/inch) 10.00 \\ PRINT INTERVAL (minutes) 1
}

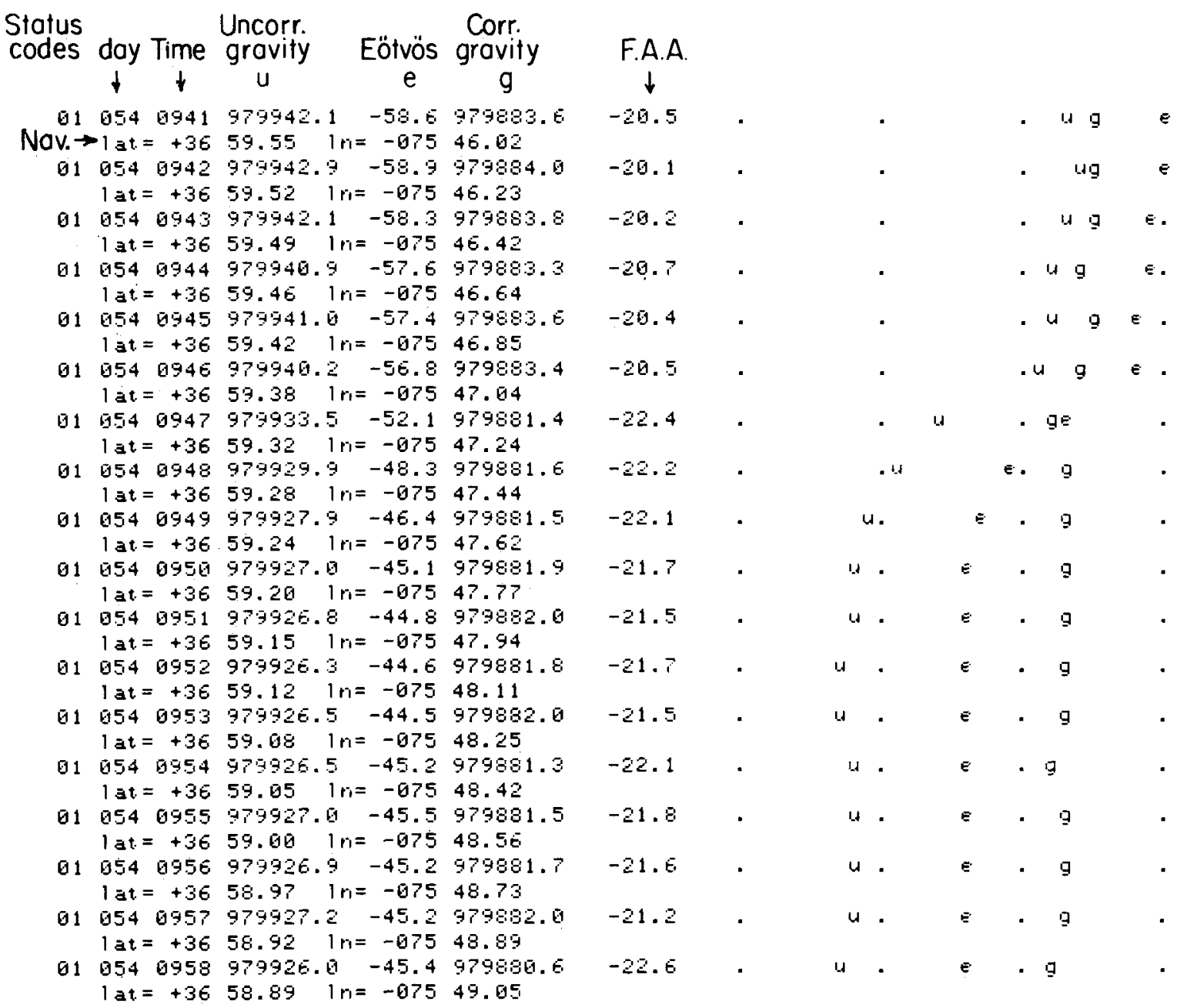

FIG. 6. Sample output of thermal line printer. Upper section contains system constants (sensor scale factor for converting pulse rate to $\mathrm{mGals}$, bias added to measuring range and manufacturer's determined drift rate applied to measurements) and display information (plot scale and print interval) which are printed each hour, or upon request. The lower section is typical 1 minute output for a well-navigated survey. The plot of Eötvös correction (e), measured gravity $(u)$, and free-air gravity anomaly $(g)$ illustrates the change in Eötvös correction for a change in speed resulting in a smooth free-air gravity anomaly trace. Scale of plot is $10 \mathrm{mGal}$ between dots. 


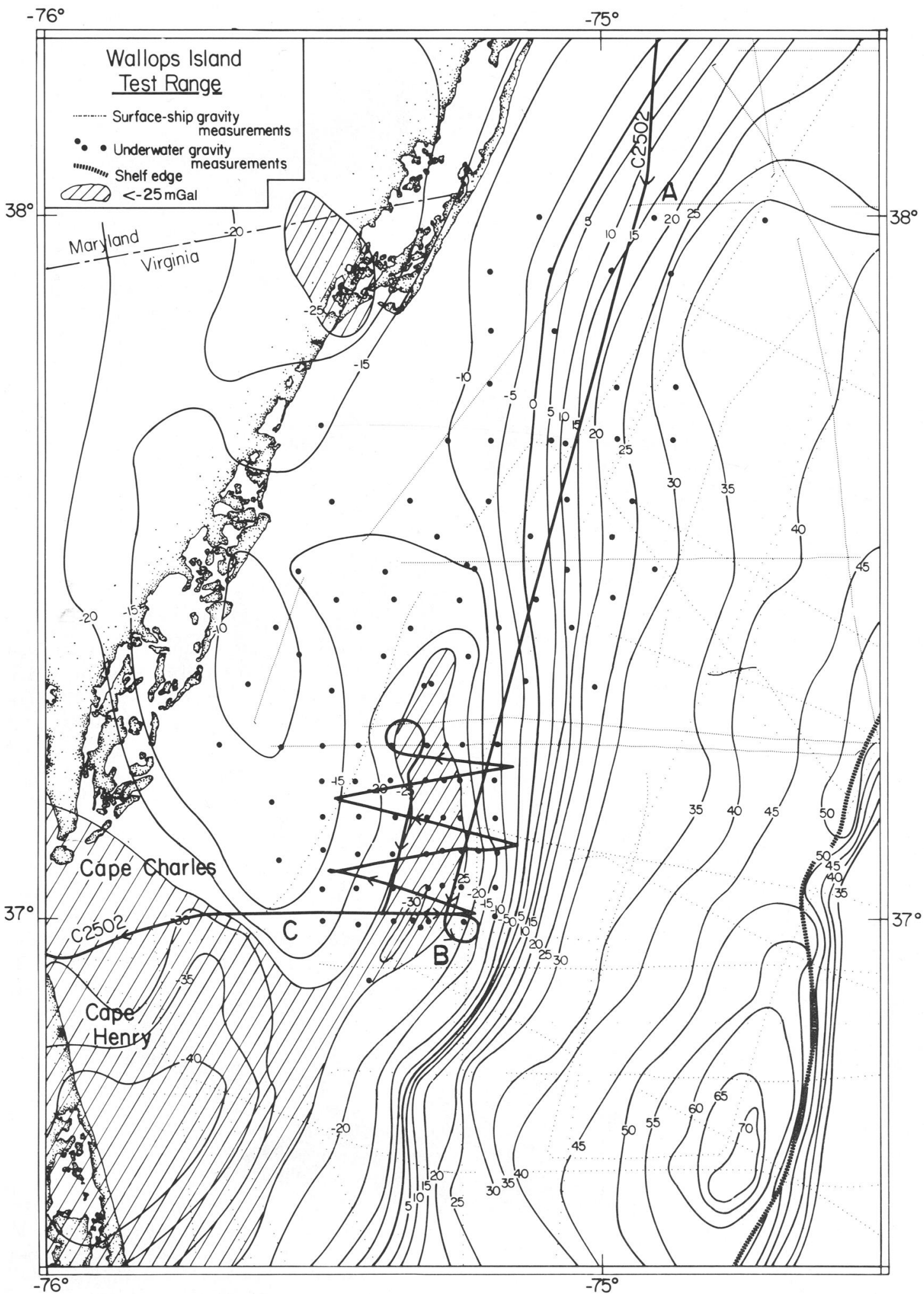

Fig. 7. Location map of $R / V$ Conrad (C2502) cruise over the Wallops Island evaluation range. Heavy line shows $R / V$ Conrad track, arrows show direction of ship motion along track, and segments A-B and B-C locate profiles seen in Figures 8 and 9 , respectively. The free-air gravity anomaly map, contoured at $5 \mathrm{mGal}$, uses the 1980 reference ellipsoid with the Potsdam correction. The map shows a prominent low (areas less than $25 \mathrm{mGal}$ are shaded) over the Wallops Island test range. Heavy dots, sea-bottom measurements (Orlin et al., 1965), and dotted lines indicate gravity data points from other cruises. Hautchers mark the edge of the continental shelf. 


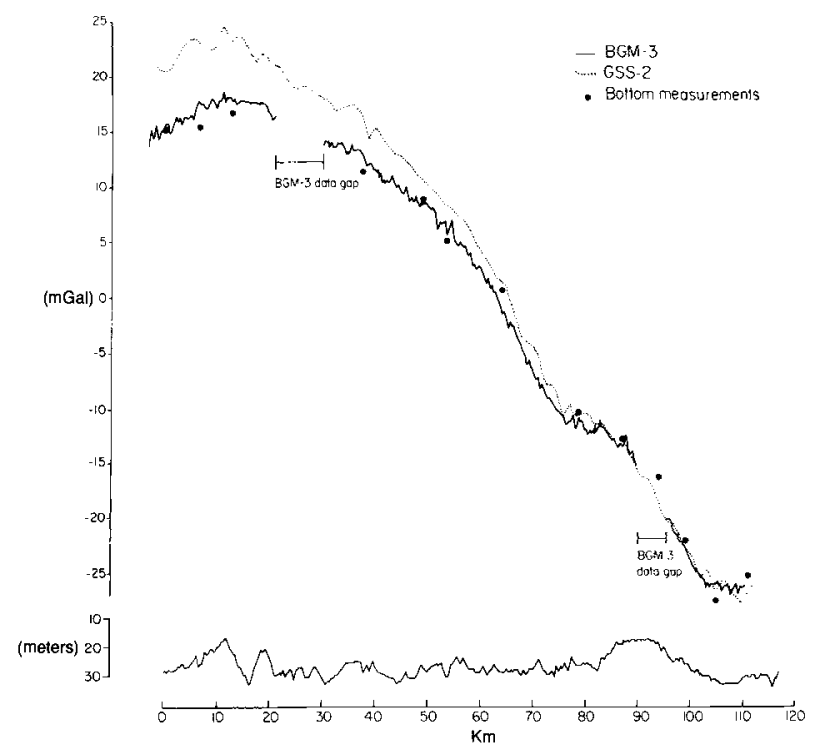

FIG. 8. Profile A-B (shown in Figure 7) crossing north to south through the test range. Solid line, BGM-3 measurements; dotted line, GSS-2 measurements. Bathymetry along track shown with large vertical exaggeration $(1: 5000)$. BGM-3 data gaps result from navigation interface problems.
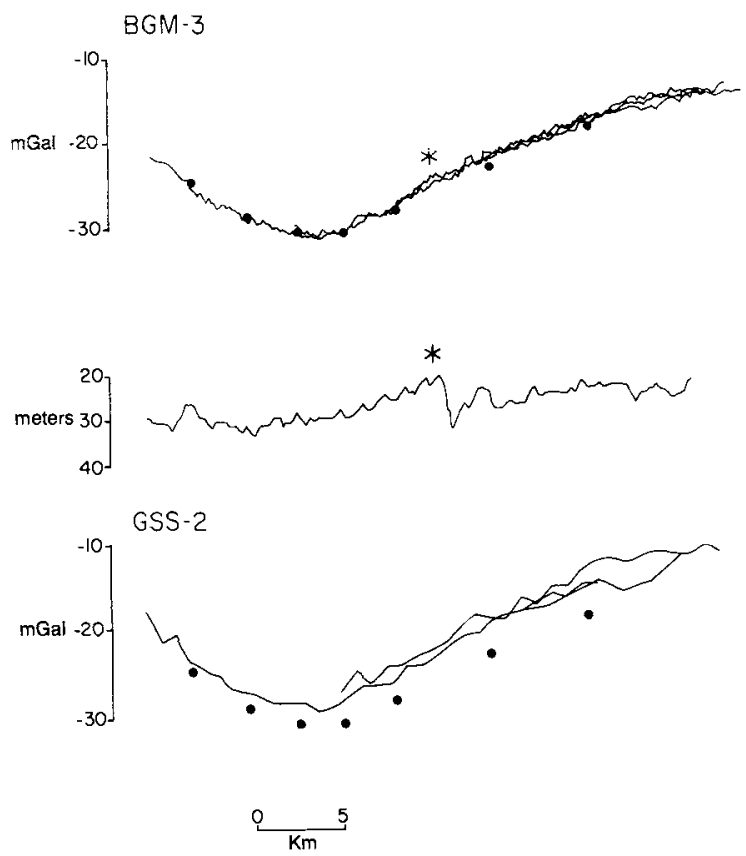

FIG. 9. Three repeat gravity anomaly profiles along B-C (shown in Figure 7) of BGM-3 data and GSS-2 data. Bathymetry is from a single track, and heavy dots are sea-bottom measurements. Asterisk indicates possible detection by BGM-3 of gravity anomaly associated with small change (less than $10 \mathrm{~m}$ ) in bathymetry.

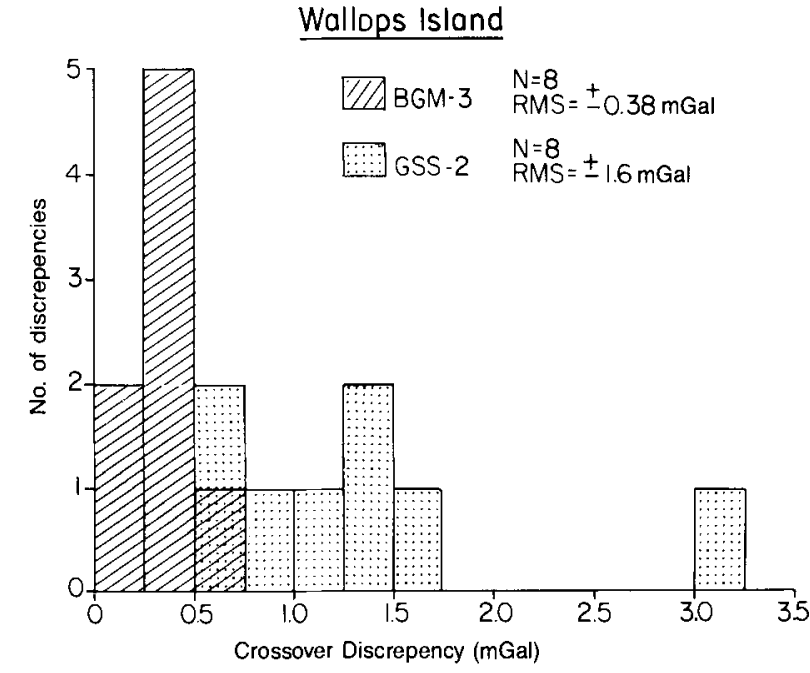

FIG. 10. Crossover discrepancies for Wallops Island test range comparing results of BGM-3 with GSS-2. Same sampling interval, navigation, and linear interpolation between points were used.

utes corresponds to a $1.5 \mathrm{~km}$ wavelength for a ship moving at 10 knots, indicating the ability of the BGM-3 gravity meter system to resolve very small features in the gravity field, despite errors inherent in the ship's navigation.

\section{OBSERVATIONS IN THE RED SEA AND BAY OF NAPLES}

The Wallops Island experiment included average quality, near-shore navigation. To present a more complete view of operating conditions, we examined BGM-3 gravity data from the northern Red Sea and Bay of Naples.

In June, 1984, $R / V$ Conrad was in the northern Red Sea on a cruise navigated by Loran $C$ and Satnav. The Loran $C$ station network was designed primarily for land positioning, thus it was not in an optimal configuration for positioning at sea.

Figure 13a shows that even with a two-step filtering scheme, the coherence between the Eötvös correction and the reduced free-air gravity anomaly remains high. We found that the combination of filters which best accounts for the ship's motion is a pair of running average filters ( 9 and 5 minutes) to the position and then a 19 minute velocity filter.

Although this heavy filtering was necessary to prevent navigation-related noise, it seriously reduces the amount of free-air gravity anomaly data that can be recovered during a course maneuver. Figure 14 shows two types of turns conducted in the northern Red Sea. Turn A (wide and slow) is the type used when towing a multichannel seismic streamer. The entire turn took about 20 minutes, during which the recorded gravity data were unusable because of repeated changes in heading. Furthermore, the heavy velocity filtering produced an additional 20 minutes of data loss. Turn B was rapid, similar to 


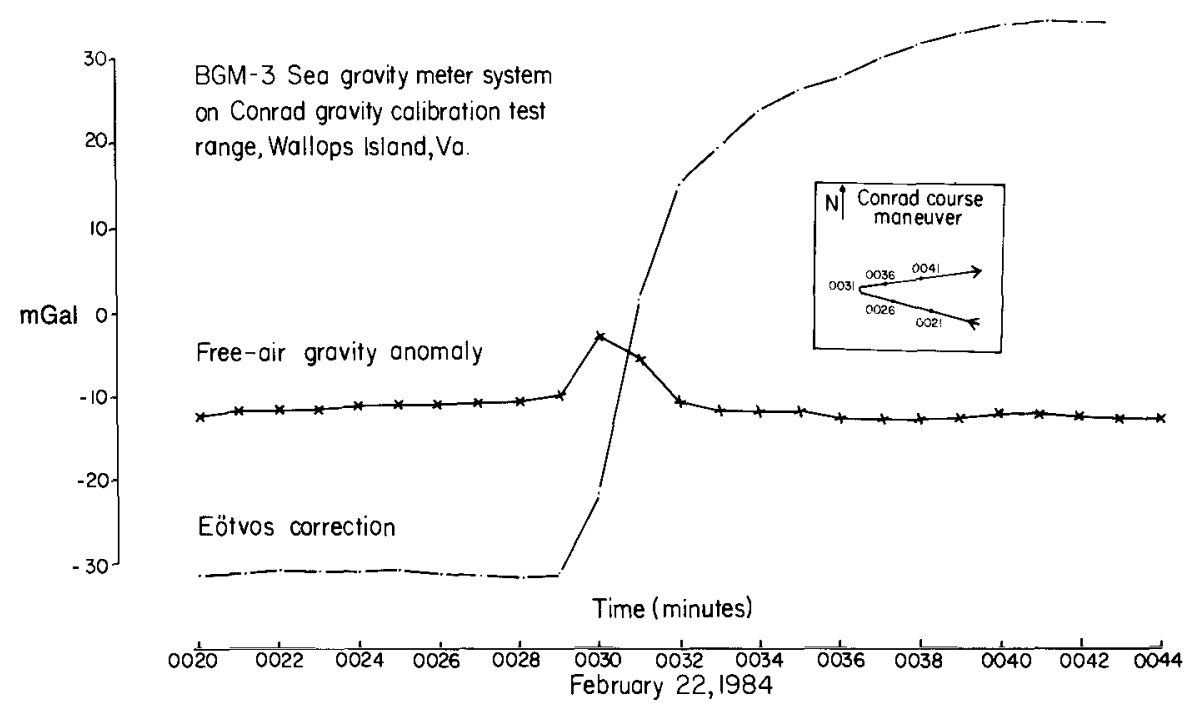

FIG. 11. Response of the BGM-3 system to a rapid 310 degree turn.

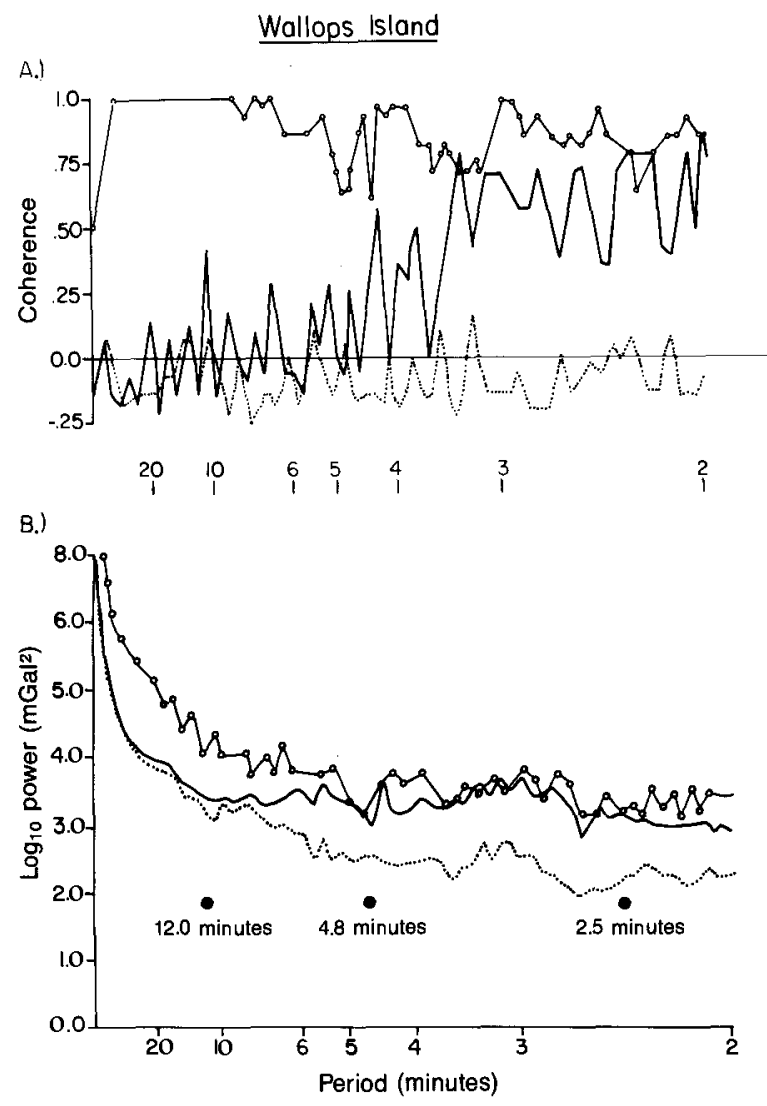

FIG. 12. Spectral analysis of BGM-3 data for 11 one hour segments over the Wallops Island test range. (a) Coherence between Eötvös correction and associated free-air gravity anomaly for three types of navigation: open circles, completely unfiltered navigation; solid lines, filtered positions and unfiltered velocities; dotted line, filtered positions and velocities. Increased filtering of navigation decreases Eötvös-to-free-air coherence and correspondingly decreases the amount of navigation noise leaking into the reduced gravity anomaly. Ideally the coherence should be zero, reflecting the lack of relationship between the ship's motion (Eötvös correction) and the free-air gravity anomaly. (b) Power spectrum of free-air gravity anomaly for range of navigation discussed in (a). Dots at 4.8 and 12.0 minutes are white noise levels for filtered positions with unfiltered velocities and completely filtered navigation.
Red Sea

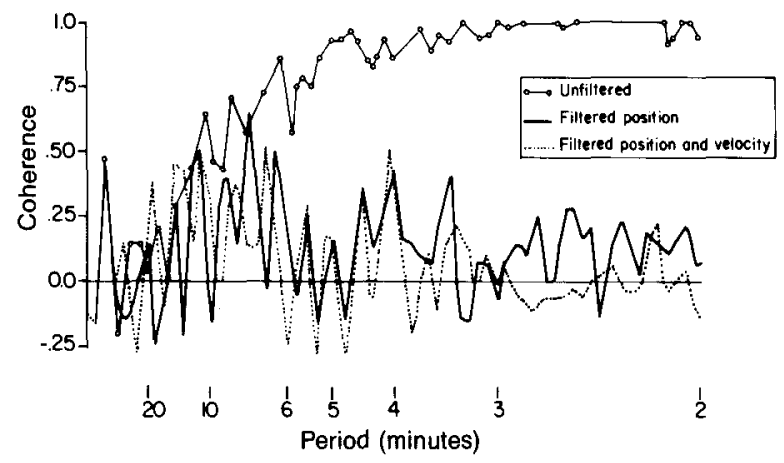

FIG. 13. Coherence between Eötvös correction and associated free-air gravity anomaly for three steps of filtering for Red Sea: unfiltered navigation, filtered positions and unfiltered velocities, and filtered velocities and position.

the turn discussed in the Wallops Island test. Despite the 4 minute recovery of the gravimeter, the total data loss exceeds 20 minutes, again reflecting heavy filtering. These observations suggest an inherent tradeoff between the accuracy required along straight-track segments and the amount of gravity that can be recovered in the vicinity of the ship.

In July, 1984, $R / V$ Conrad conducted an intensive gravity survey of the Bay of Naples. The survey, covering an area of $900 \mathrm{~km}^{2}$, was navigated by a miniranger system consisting of three shore-based transmitters integrated with Loran $\mathrm{C}$ positions and velocities over-the-ground from a Furuno speed log. The survey resulted in a total of 528 internal crossovers of the ship track. 238 crossovers met the criterion of not being within 3 minutes of a turn, and they provided a statistically much improved data base from which system accuracy could be assessed. The mean and the rms crossover discrepancies were 0.1 and $\pm 0.7 \mathrm{mGal}$, respectively. Figure 15 shows a free-air gravity anomaly map of the survey area. Although the map has been contoured at a $5 \mathrm{mGal}$ interval, the crossover analysis suggests that a finer interval would have been permitted. 


\section{DISCUSSION}

The BGM-3 sea gravity meter system (with adequate navigation) is capable of submGal accuracy and resolution of wavelengths of 1 to $2 \mathrm{~km}$. Assuming the system has a resolution of $1 \mathrm{mGal}$ at wavelengths of 1 to $2 \mathrm{~km}$, a wider range of geological problems may be addressed than was possible using previous systems.

Figure 16 schematically illustrates the accuracy requirements needed to address different geologic problems with a variety of spatial wavelengths. Also shown are the accuracies for the BGM-3 and GSS-2 gravity meter systems based on the results of this paper and previously published reports. The accuracy and resolution of the BGM-3 system are such that it can detect a new class of geologic features, inciuding mud volcanos, incised channels, oblate fans, and other sedimentary structures. The advent of the GPS, with positional accuracies of better than $15 \mathrm{~m}$ (Ligon, 1985), may make it possible to detect temporal variations in the gravity field arising from storm-driven sediment waves and magma migration in the uppermost crust.

Satellite radar altimetry, beginning with GEOS-3 in 1975, narrowed the gap between the resolution that was achievable with surface ships and from space techniques. The highresolution SEASAT mission further narrowed this gap such that features in the gravity field with an accuracy of $\pm 7 \mathrm{mGal}$
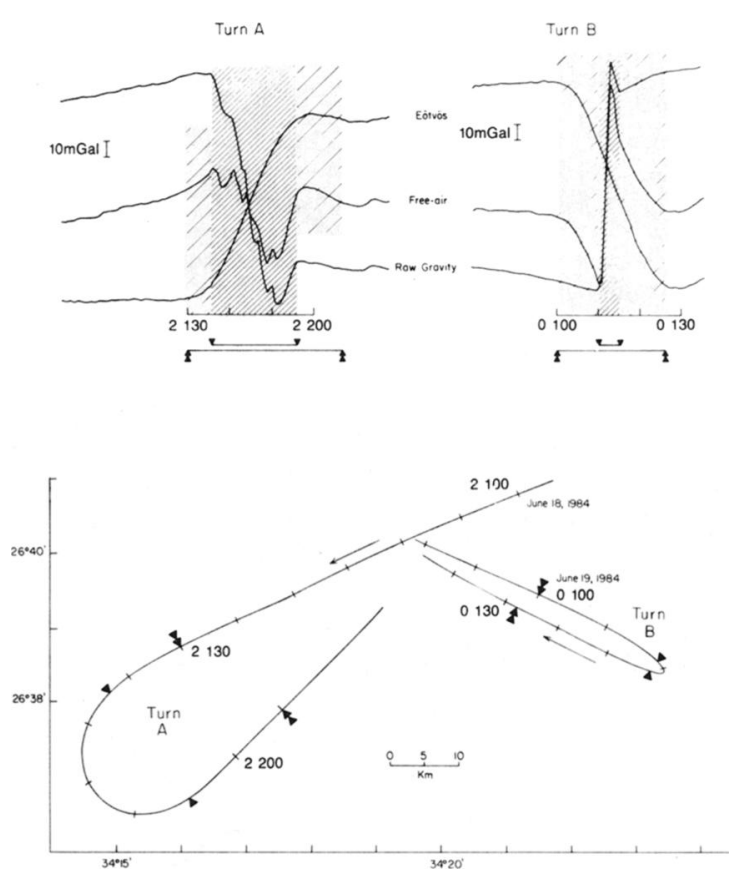

FIG. 14. BGM-3 system response to two ship maneuvers; one slow (turn A) and one fast (turn B). Single arrows and densely hautchered regions indicate periods of unrecoverable gravity data due to platform response and internal filter characteristics. Double arrows and light hautchering mark data unrecoverable due to heavy navigation filtering, exaggerating the effect of the turns. Filtering doubles the amount of data lost around turns while improving the along-track data quality. Profiles show raw or measured gravity, Eötvös correction from heavily filtered navigation, and resultant free-air gravity anomaly. with wavelengths of about $200 \mathrm{~km}$ have been recovered from altimeter data (Rapp, Pers. comm.). This resolution impinged on the utility of surface-ship gravity measurements, especially those obtained with the GSS-2 system. We believe the BGM-3 sea gravity meter system has extended the useful wave band of marine gravity down to a level unachievable by existing space techniques.

\section{ACKNOWLEDGMENTS}

The successful installation of the BGM-3 sea gravity system on $R / V$ Conrad would not have been possible without the help of many individuals. We particularly thank L. Meister and N. Burnfield of Bell Aerospace, Textron and I. Bitte of LamontDoherty who supervised the installation of the system, P. Buhl and F. Martinez for help in providing navigation at sea, and A. Shor, J. Cochran, and K. Crane for their role as chief scientists during the Wallops Island, Red Sea, and Bay of Naples surveys. We thank M. Langseth and J. Cochran for critically reviewing the manuscript.

This work was supported by U.S. Dept. of Defense (Universities Instrumentation Program) grant N00014-83-0168 and National Science Foundation grant OCE 82-16945. LamontDoherty Geological Observatory contribution 3959.

\section{REFERENCES}

Bell Aerospace, Textron, 1978, Marine gravity measuring system: Tech. Rep. D6109-95003, revision A.

Bowin, C., Aldrich, T. C., and Folinsbee, R. A., 1972, VSA gravity meter system: Tests and recent developments: J. Geophys. Res. 77 2018-2033.

Browne, B. C., 1937, The measurement of gravity at sea: Monthly notes, Roy. Astr. Soc., Geophys. Suppl. 4, 271-279.

Burnfield, R. N., 1981, The BGM-3 Shipboard meter 2nd Internat. Symp. on Inertial Technology for Surveying and Geodesy: Banff.

Graff, A., 1958, Das Seegravimeter: Z. Instrumentenkd, 60, 151-162.

Graff, A., and Schulze, R., 1961, Improvements on the sea gravimeter GSS-2, J. Geophys. Res., 66, 1813-1821.

Haworth, R. T., 1967, Notes on the construction and use of a cross coupling computer: Bedford Inst. Ocean., internal note 67-5-I.

LaCoste, L. J. B., 1959, Surface ship gravity measurements on the Texas A\&M College ship Hidalso: Geophysics, 24, 309-322.

1973, Crosscorrelation method for evaluating and correlating shipboard gravity dat a: Geophysics, 38, 701-709.

LaCoste, L. J. B., and Harrison, J. C. 1961, Some theoretical considerations in the measurement of gravity at sea: Geophys. J., 5, 89-103.

Ligon, J. M., 1985, NAVSTAR-GPS at sea results: Marine Geodesy, 9. $227-261$

Newman, L. D., and Talwani, M., 1973, Accelerations and errors in gravity measurements on surface ships: J. Geophys. Res., 77, 43304338 .

Orlin, H., Bassinger, B. G., and Gray, C. H., 1965, Gravity equipment evaluation range Cape Charles, Va., Wallops Island, Va:: Joint Rep., U.S. Dept. of Commerce Coast and Geodetic Survey, and U.S. Naval Ocean. Office, Dept. of Def.

Pierce, J. W., Change C. C., and Loncarevic, B. D., 1984, Operational experience with the Bodenseewerk KSS-30 marine gravity meter: Can. Soc. Explor. Geophys., abstract.

Talwani, M., 1966, Some recent developments in gravity measurements aboard surface ships, in Orlin, H., Ed., Gravity anomalies unsurveyed areas: Am. Geophys. Union Geophysical Monograph 9., $31-48$.

., 1971, Gravity, in Maxwell, A., Ed., The sea: John Wiley and Sons.

Tomodo, Y., and Kanamori, H., 1962, Tokyo surface ship meter Alpha-1, Japanese: J. Geophys., 7, 116-145.

Vening Meinesz, F. A. 1929, Theory and practice of pendulum observations at sea: The Netherlands Geodetic Commission, Tech. Boekhandelin Drukkerij.

1941, Theory and practice of pendulum observations at sea II: The Netherlands Commission.

Wing, C. G., 1969, MIT vibrating string surface ship gravimeter: J Geophys. Res., 74, 5882-5894.

Woollard, G. P., and Rose, J. C., 1963, International gravity measurements: Soc. Explor. Geophys.

Worzel, J. L., 1965, Pendulum gravity measurements at sea 19361959: John Wiley and Sons. 


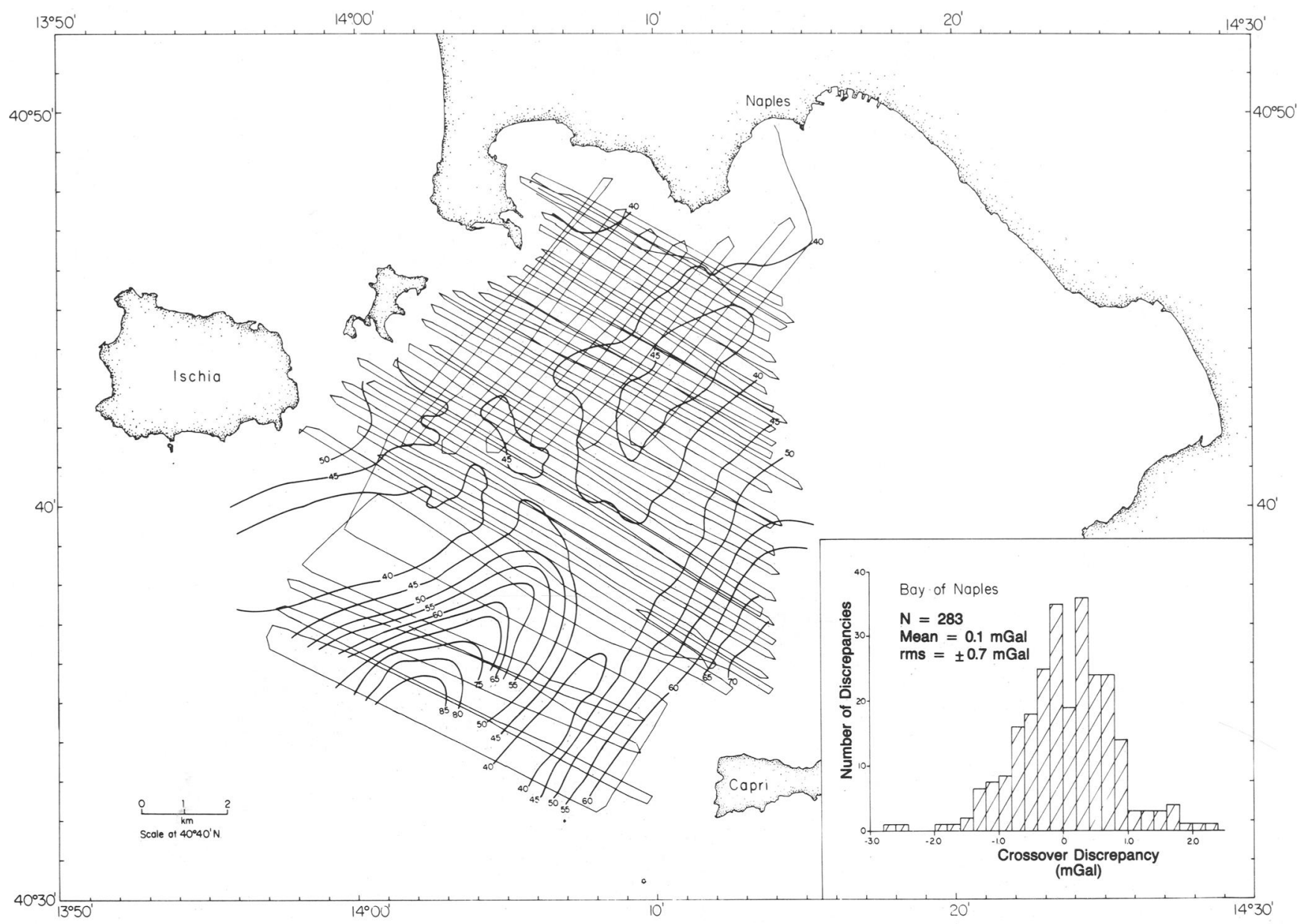

FiG. 15. The free-air gravity anomaly map of the Bay of Naples is contoured at $5 \mathrm{mGal}$. Fine lines indicate $R / V$ Conrad track (C2508). Histogram is based on 283 crossover discrepancies. rms crossover discrepancy of .7 mGal suggests that contour interval could be increased to $2 \mathrm{mGal}$ to resolve the field further and to keep to within the limits of the data.

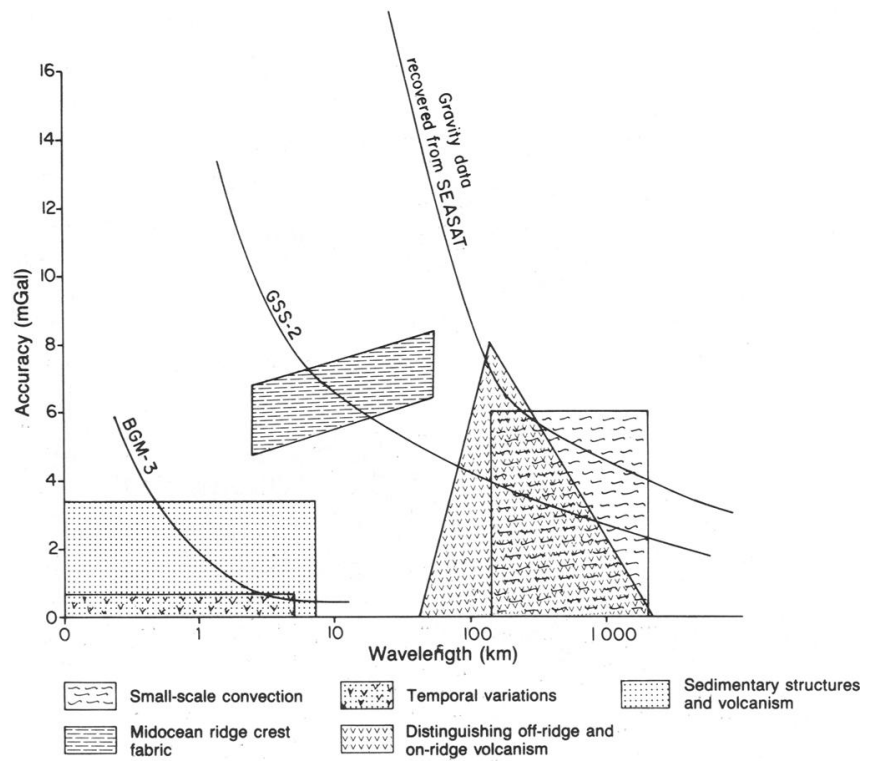

FIG. 16. Schematic diagram of accuracy and resolution requirements for marine gravity studies. 


\section{APPENDIX A}

The Wallops Island test range data were connected by base station "tie-ins" into the U.S. gravity network.

A value of $980275.5 \mathrm{mGal}$ for Piermont Pier was used, based on a value of $980254.6 \mathrm{mGal}$ in Room 106 of the oceanography building at Lamont-Doherty. The Oceanography Building site is in turn tied into Lamont Hall (Worzel, 1965) which is one of the "fundamental" base stations in the United States (Woollard and Rose, 1963, p. 331) occupied by a Gulf-Western pendulum apparatus. In the tie-in, an un-

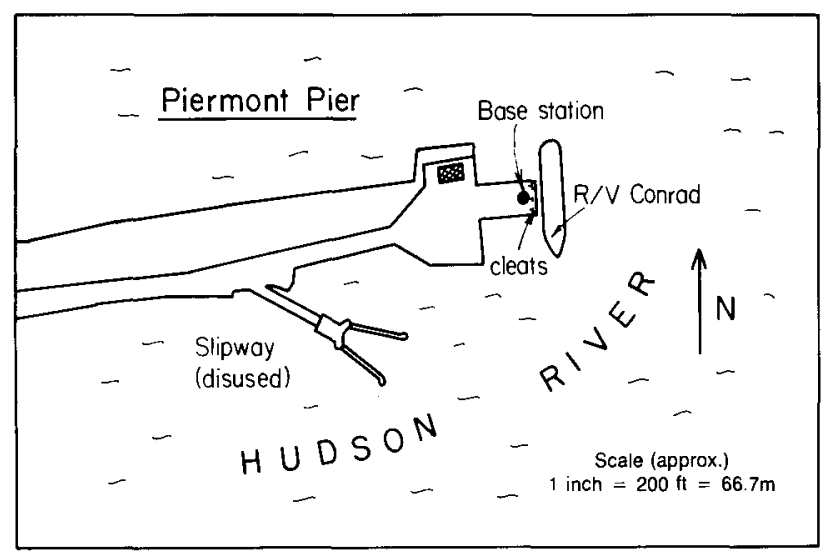

FIG. A-1.

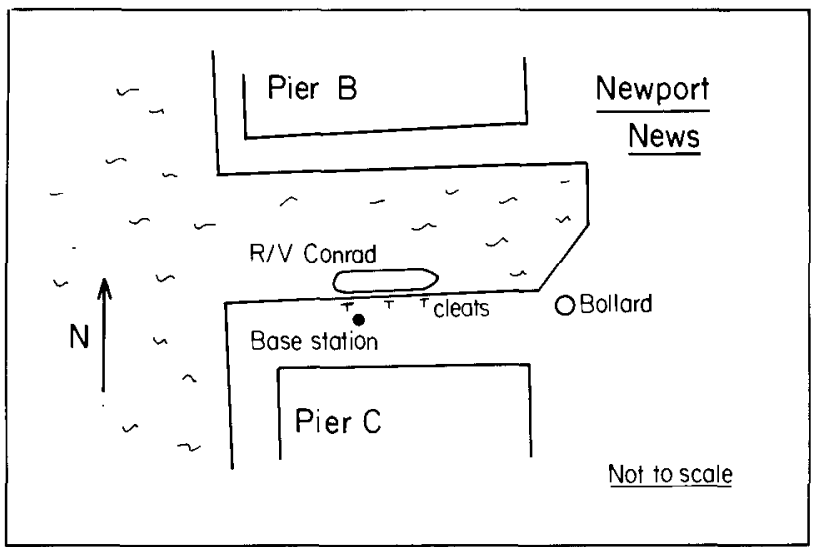

FIG. A-2. corrected value for the Potsdam error value of 980258.9 mGal was assumed for Lamont Hall.

A value of $979878.9 \mathrm{mGal}$ was used for the Norfolk Municipal Airport based on site WA 166 (Woollard and Rose, 1963, p. 133). As was the case for the oceanography building, this site is tied into the U.S. gravity network of fundamental base stations and is uncorrected for the Potsdam error.

The details of the tie-ins at each base station are given in Tables A-1 and A-2 and Figures A-I and A-2.

Table A-1. Gravity tie-in.

\begin{tabular}{|c|c|c|c|}
\hline \multicolumn{3}{|c|}{$\begin{array}{c}\text { February 1, } 1984 \\
\text { Piermont, N.Y. } \\
\text { Observer: Robin Bell } \\
\text { Meter: Lacoste, G-70 } \\
\text { (interval } 1.03620 \text { ) }\end{array}$} & $\begin{array}{c}\text { Base station } \\
\text { Piermont Pier (Figure A-1) } \\
\text { (established 1984 from } \\
\text { Oceanography Building) } \\
980275.7\end{array}$ \\
\hline \multirow[b]{2}{*}{ Base } & Time & $\begin{array}{l}\text { LaCoste } \\
\text { dial reading }\end{array}$ & Average \\
\hline & $\begin{array}{l}1239 \\
1241 \\
1243\end{array}$ & $\left.\begin{array}{ll}3 & 769.430 \\
3 & 769.410 \\
3 & 769.450\end{array}\right\}$ & 3769.43 \\
\hline Pier & $\begin{array}{l}1249 \\
1253 \\
1256\end{array}$ & $\left.\begin{array}{ll}3 & 769.971 \\
3 & 769.970 \\
3 & 769.974\end{array}\right\}$ & 3769.972 \\
\hline Base & $\begin{array}{l}1259 \\
1301 \\
1303\end{array}$ & $\left.\begin{array}{ll}3 & 769.413 \\
3 & 769.425 \\
3 & 769.420\end{array}\right\}$ & 3769.419 \\
\hline \multicolumn{4}{|c|}{$\begin{array}{l}\text { Drift: negligible } \\
\begin{aligned} \Delta g(\text { pier to base }) & =(\Delta \text { intervals }) \times \text { constant } \\
& =(.547) \times 1.036=.57 \mathrm{mGal}\end{aligned}\end{array}$} \\
\hline \multicolumn{2}{|c|}{$\begin{array}{l}\text { Pierside value } \\
\text { BGM-3 elevation } \\
\text { Free-air correctio }\end{array}$} & \multicolumn{2}{|c|}{$\begin{array}{l}980276.3 \\
-1.6 \mathrm{~m} \\
.4 \mathrm{mGal}\end{array}$} \\
\hline \multicolumn{3}{|c|}{$\begin{array}{l}\text { Tie value corrected } \\
\text { to meter level }\end{array}$} & \\
\hline \multicolumn{2}{|c|}{$\mathrm{BG} \mathrm{M}-3$ reading } & 9802 & \\
\hline \multicolumn{2}{|c|}{ Mis-tie } & -2.0 & $\mathrm{aGal}$ \\
\hline
\end{tabular}


Table A-2. Gravity tie-in.

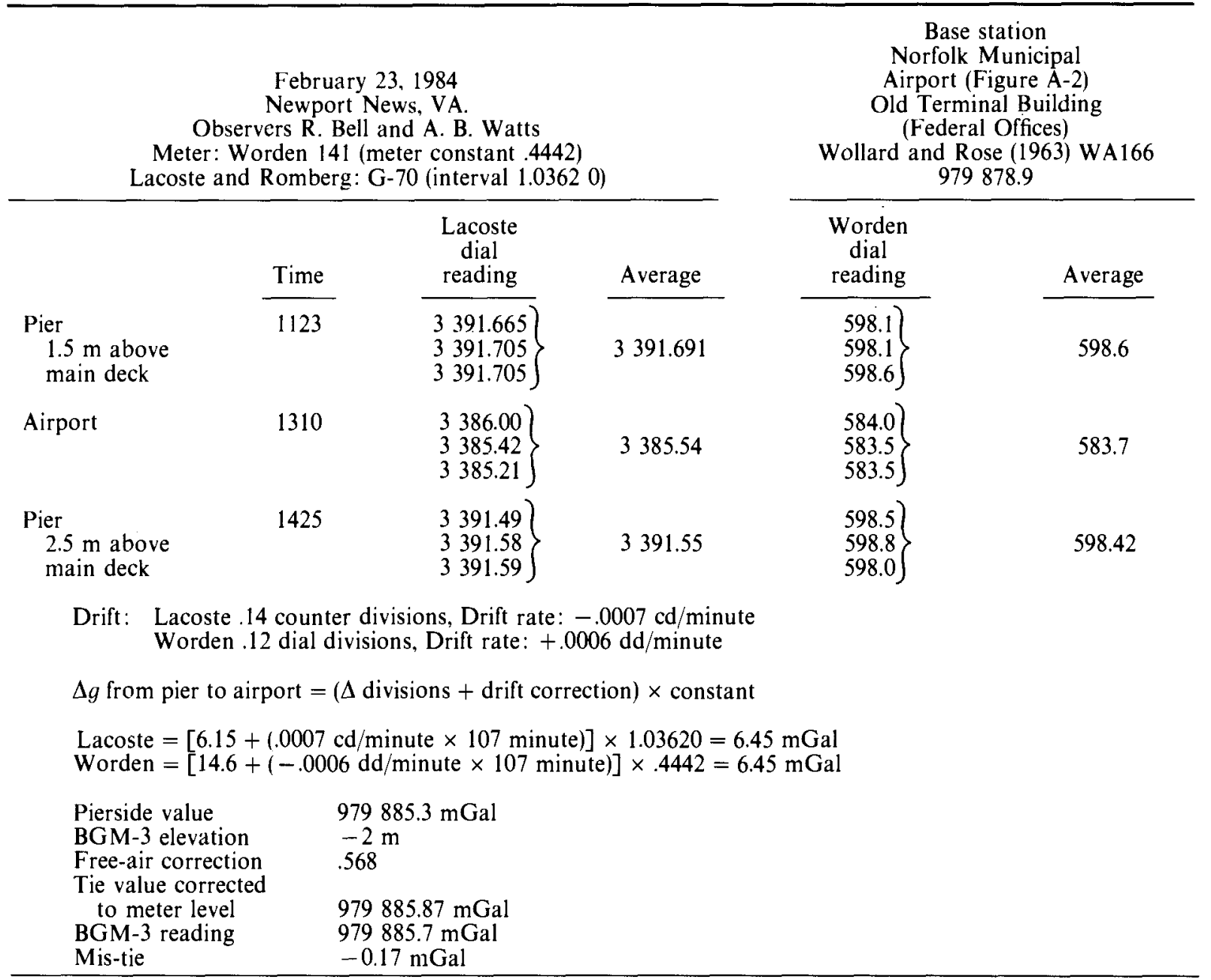

\section{APPENDIX B}

In port, the measuring capabilities of the BGM-3 are largely limited by the ship's motion and the ocean tides. In quiet harbors with significant tidal ranges such as St. Johns, Newfoundland, the motion associated with the tides can be easily distinguished in the BGM-3 data and simply corrected. The ship's motion observed in ports becomes a serious problem, however, in the precruise testing of the system components and determining the actual port value.

The ship's long-period motions are irregular, and are primarily observed in berths close to heavily used shipping channels. Apparently, the wakes from passing traffic, when convolved with the shallow water and the damped spring behavior of a ship secured to a dock, are sufficient to produce signals detectable by the BGM-3 sensor. Generally, this noise (up to $\pm 1 \mathrm{mGal}$ ) subsided markedly at night as the traffic decreased, permitting precruise system testing.

We have documented a single case where this in-port noise was excessive (up to $\pm 7 \mathrm{mGal}$ ), periodic (period of $110 \mathrm{~s}$ ), and apparently unrelated to passing traffic. This instance occurred in November, 1984 when $R / V$ Conrad was berthed in San Juan, Puerto Rico. Taking into account the attenuation of BGM-3's internal filter, this noise level suggests $3 \mathrm{~m}$ of vertical motion (or more than $10 \mathrm{~m}$ of horizontal motion). Neither of these motions was observed, and a thorough testing of all system components failed to reveal any malfunctions. The oscillation decreased in amplitude as the ship was untied from the dock and disappeared completely as the ship sailed. 